\title{
THE INTERACTION OF DENTAL GLASS-IONOMER CEMENTS WITH BUFFER SOLUTIONS
}

\author{
JACEK KŁOS*, **, BEATA CZARNECKA**, ${ }^{*}$ JOHN W. NICHOLSON*** \\ *Department of Physical Chemistry, Faculty of Chemistry, Adam Mickiewicz University of Poznań, \\ Ul. Uniwersytetu Poznańskiego 8, 61-614 Poznań, Poland \\ **Department of Biomaterials and Experimental Dentistry, Dental Institute, University of Medical Sciences, \\ ul Bukowska 70, 60-812 Poznań, Poland \\ ***Bluefield Centre for Biomaterials, 67-68 Hatton Garden, London, EC1N 8JY, United Kingdom and Dental Physical Sciences, \\ Barts \& The London School of Medicine and Dentistry, Queen Mary University of London, \\ Mile End Road, London, E1 4NS, UK \\ \#E-mail: john.nicholson@bluefieldecentre.co.uk
}

Submitted December 19, 2020; accepted February 1, 2021

Keywords: Glass-ionomer cements, Buffer solutions, Mass gain, Compressive strength

Four brands of glass-ionomer cement (Fuji IX GP, Riva, Ketac Molar and Chemfil Superior) have been stored in aqueous media comprising distilled water, or phosphate buffer solutions at pH 5.42, 6.91 and 8.13 at $37{ }^{\circ} \mathrm{C}$ for 7 days. Cements differed widely in their response. All took up small amounts of water in distilled water, and had high compressive strengths. Ketac Molar showed no differences in any of the buffer solutions, but gained small amounts in mass, and showed high compressive strength in all storage media. Conversely Chemfil Superior was adversely affected by all three buffers, and Fuji IX and Riva were adversely affected by the buffers at $\mathrm{pH} 6.91$ and 8.31. The reasons for these differences were not clear, but the fact that the buffer closest to neutral (pH 6.91) caused significant damage to three of the cements studied shows that this is not a simple effect of $\mathrm{pH}$.

\section{INTRODUCTION}

Glass-ionomer cements are partly ceramic materials that are widely used in dentistry for a variety of purposes. These include full restoratives, liners and bases, fissure sealants and orthodontic adhesives for fixation of brackets [1]. They are prepared from special basic glass powders and aqueous solutions of polymeric acid. In clinical glass-ionomers, the latter are one of polyacrylic acid, acrylic/maleic or acrylic/itaconic copolymer or the copolymer of 2-methylene butanedioic acid with propenoic acid [2]. Experimental cements have been made from other polymeric acids, such as polyvinyl phosphonic acid [3], but the three polymers named are the ones that are employed in commercial materials for use in the clinical practice.

The glasses are complex substances made from appropriate blends of calcium or strontium oxide, cryolite $\left(\mathrm{Na}_{3} \mathrm{AlF}_{6}\right)$ and other fluoride and/or phosphate compounds, such as $\mathrm{CaF}_{2}, \mathrm{SrF}_{2}, \mathrm{AlPO}_{4}$, etc. The preparation of these glasses involves melting the components at temperatures in the range $1100-1500{ }^{\circ} \mathrm{C}$, followed by holding the mixture at this temperature for a specified period of time to allow fully mixing and vitrefication to occur [4]. The melt is then cooled rapidly by pouring into cold water, which causes fracture into pieces of glass frit.
Despite the speed of quenching, the glasses may undergo partial phase separation as they cool $[5,6]$. This results in the occurrence of two phases, one of which is more basic than the other, and hence more susceptible to acid attack during setting.

The hardening of these materials is an acid-base reaction [1] that initially involves the formation of simple metal salts of the polymeric acid, e.g. sodium and calcium polyacrylate. Slightly later, aluminium polyacrylate can be detected [7] and in due course some sort of insoluble inorganic network forms from the partially degraded glass [8]. This network appears to be based on a phosphate species [9].

These various setting processes result in a hardened material that has a very complicated structure. One feature of it is that the polymeric component is not fully neutralised, but retains a small proportion of unreacted carboxylic acid groups trapped within the structure [7]. This means that the cement has the composition of a classic acid buffer, i.e. a weak acid in association with a salt of the same acid [10]. Studies have confirmed that glass-ionomers are capable of behaving as buffers, since they will shift the $\mathrm{pH}$ of both weakly acidic and weakly basic solutions towards neutral $[11,12]$. This behaviour is enhanced by the presence of unreacted glass powder in the set cement, and this is itself capable of reacting 
with an external acid solution [13]. Whatever the details of the process, there is considerable evidence that glassionomer cements can affect the $\mathrm{pH}$ of their immediate surroundings and this may be a mechanism by which restorations protect adjacent tooth tissue from acid attack [12].

In the mouth, glass-ionomers encounter saliva, which is itself a natural buffer solution [14]. This raises the question of how the buffering effect of glass-ionomers might be affected by external buffer solutions. Also, because experiments show that the mechanical strength of glass-ionomers is influenced by storage solutions of different compositions [15-17] there is also the question of how an external buffer solution might affect the strength of glass-ionomer cements stored in it. These two questions are addressed in the current paper. The work reported here was based on two null hypotheses, namely (i) that glass-ionomers will not shift the $\mathrm{pH}$ of an external buffer solution, and (ii) that the compressive strength of glass-ionomers will not be a altered by storage in buffer solutions of different $\mathrm{pH}$ values.

\section{EXPERIMENTAL}

\section{Materials and methods}

Four different commercial glass-ionomer cements, all of the conventional acid-base type, were used in these experiments. Details appear in Table 1.

Table 1. Materials employed.

\begin{tabular}{lll}
\hline Material & Manufacturer & Identifier \\
\hline Fuji IX GP & GC, Japan & 170408A, ref 003274 \\
Riva Self Cure & SDI, Australia & C1704101F \\
Ketac Molar & 3M Espe, Germany & Lot 41362018 \\
Chemfil Superior & Dentsply, Germany & Lot 18040 00 454 \\
\hline
\end{tabular}

Cylindrical specimens of dimensions $6 \mathrm{~mm}$ high vs $4 \mathrm{~mm}$ diameter were prepared by mixing the cements in accordance with the manufacturers' instructions. Mixing of the glass powders was performed using a metal spatula on a glass block, and once prepared, freshly mixed pastes were transferred to split metal moulds, and allowed to harden for one hour in an incubator at $37^{\circ} \mathrm{C}$. Sets of 6 specimens were prepared for each type of cement for each experiment. Following hardening, specimens were removed form the moulds, weighed, and placed in one of four storage solutions, details of which are shown in Table 2. These consisted of phosphate buffer solutions with $\mathrm{pH}$ values $5.42,6.91$ and 8.13 respectively, prepared by dissolving $\mathrm{KH}_{2} \mathrm{PO}_{4}$ and $\mathrm{K}_{2} \mathrm{HPO}_{4}$ (both anhydrous analytical grade reagents, supplied by AKTYN, Suchy Las, Poland) at $1 \mathrm{~mol} \cdot \mathrm{dm}^{-3}$ concentrations, then mixing the solutions in appropriate proportions (Table 2). In addition, deionised water at $\mathrm{pH} 5.45$ as a control. In all cases, a single cylinder of cement was stored in an individual $5 \mathrm{~cm}^{3}$ volume of aqueous medium at $37^{\circ} \mathrm{C}$ for 7 days, meaning that each data point represents the mean of six individual measurements.

Table 2. Storage solutions employed.

\begin{tabular}{lcc}
\hline Storage medium & $\mathrm{pH}$ & $\begin{array}{c}\text { Composition }\left(\mathrm{cm}^{3}: \mathrm{cm}^{3}\right) \\
\left(1 \mathrm{M} \mathrm{K}_{2} \mathrm{HPO}_{4}: 1 \mathrm{M} \mathrm{KH}_{2} \mathrm{PO}_{4}\right)\end{array}$ \\
\hline Phosphate buffer & 5.42 & $5: 95$ \\
Phosphate buffer & 6.91 & $55: 45$ \\
Phosphate buffer & 8.13 & $95: 5$ \\
Deionised water & 5.45 & Deionised water only \\
\hline
\end{tabular}

After storage, specimens were removed from the storage medium, weighed, and their compressive strength was determined as described in ISO9917 [18] using a Universal Testing machine (Hounsfield H5KS, Redhill, Surrey, UK) with loading at $1.0 \mathrm{~mm} \cdot \mathrm{min}^{-1}$. Loads at failure were converted to compressive strength and means and standard deviations determined for each ce-ment and storage medium combination.

The $\mathrm{pH}$ values of the storage solutions were measured before and after storage using a $\mathrm{pH}$ meter (Model ULAB 2002, Tele-Eko Projekt, Poland) that had previously been calibrated at $21 \pm 1{ }^{\circ} \mathrm{C}$ with standard buffer solutions of $\mathrm{pH} 4.0,7.0$ and 10.0 (supplied by $\mathrm{POCH}$ Spółka Akcyjna, Gliwice, Poland). Each solution was measured before and after storage of the specimens.

Results of compressive strength, mass change and $\mathrm{pH}$ of storage medium were expressed as means and standard deviations. Differences between values were tested for significance by 1-way ANOVA and the Tukey HSD test.

\section{RESULTS}

Storage of cement samples in buffer solutions and in distilled water was found to lead to minor changes in external $\mathrm{pH}$ in the case of buffer solutions, and to slightly larger changes in distilled water. As shown in Table 3, the general trend in the latter was to shift $\mathrm{pH}$ towards neutral.

Results for mass change and compressive strength are shown in Tables 3 and 4 respectively. One-way ANOVA showed that most sets of data contained significant differences. Mass generally increased on storage (Tab. 4), the only exception being Fuji IX in the buffer at $\mathrm{pH}$ 6.91. Storage in water gave results that were not significantly different for Fuji IX GP, Riva and Ketac Molar, but which were significant higher $(\mathrm{p}<0.05)$ for Chemfil Superior. For these three brands, too, there was no significant difference between the mass gain in distilled water and in the buffer at $\mathrm{pH}$ 5.42. Here again Chemfil Superior was different, showing a significant 
greater mass increase in $\mathrm{pH} 5.52$ than in distilled water $(\mathrm{p}<0.05)$. Ketac Molar was the most resistant to the effects of the various storage media, with no significant differences between mass gains at $\mathrm{pH} 5.42, \mathrm{pH} 6.91$ and distilled water. For this material, the mass change in $\mathrm{pH} 8.13$ was significantly lower than in all the other storage media $(\mathrm{p}<0.05)$.

Riva and Chemfil Superior both showed substantial mass gains in the buffers at $\mathrm{pH} 6.91$ and 8.13. In the case of Chemfil Superior in $\mathrm{pH} 8.13$, there was so much gain in mass due to swelling in the storage medium that it made the specimens too soft to test their compressive strength.

Values of compressive strength are shown in Table 5 and were affected to an extent by the storage medium. The exception was Ketac Molar, where there were no significant differences with any storage medium. With the other materials, storage in buffer solution at $\mathrm{pH} 5.42$ and in distilled water $(\mathrm{pH}$ 5.45) gave no significant difference in strength. For Fuji IX GP and Riva, storage at $\mathrm{pH} 8.13$ caused the cements to weaken significantly ( $p>0.01$ in both cases). In general, this seemed to be the most damaging storage medium for this group of glassionomer cements.

For the cements Fuji IX GP, Riva and Chemfil Superior, storage at $\mathrm{pH} 6.91$ led to significant reductions in strength ( $p<0.01$ in all three cases) compared with both the pH 5.42 buffer and distilled water. However, in the case of both Riva and Chemfil Superior, this reduction was not as substantial as for storage at $\mathrm{pH} 8.31$. This meant hat the strengths under these conditions were significantly different $(\mathrm{p}>0.01)$ from those stored at $\mathrm{pH} 8.13$.

\section{DISCUSSION}

The results of this study show that the external medium has an influence on glass-ionomer cements stored in it. The experiments were conducted using an arbitrary ratio of specimen size to storage volume. The specimen geometry is the recommended in the relevant International Standard [18], and the volume of liquid $\left(5 \mathrm{~cm}^{3}\right)$ has been used in numerous studies of both fluoride exchange [20,21] and $\mathrm{pH}$ change [22]. The storage time of 1 week was also arbitrary, and chosen to allow a substantial interaction to take place between the specimens and their storage solutions. Studies of this type have previously used various storage times, ranging from 24 hours to six months, and in general, times of at least a week have been necessary to observe changes in either the solution composition or the specimen.

In the present study, the influence of the storage medium was found to vary with the brand, with Ketac Molar being hardly affected at all. It had excellent resistance to all three buffer solutions, regardless of their $\mathrm{pH}$, and also to water. In all cases, it showed a modest increase in mass, showing that it had taken up some of the storage liquid, but an all cases this uptake was small and there was no effect on compressive strength.

This result is surprising in the light of results obtained for the other materials, specifically for the buffer solution at $\mathrm{pH}$ 8.31. All three were weakened in this storage medium, and in the case of Chemfil Superior this weakening was catastrophic. This material took up substantial amounts of solution and it was affected to the extent that samples were too soft to test for strength.

Table 3. pH values after 7 days in different storage media (standard deviations in parentheses).

\begin{tabular}{lcccr}
\hline Material & $\mathrm{pH} 5.42$ & $\mathrm{pH} \mathrm{6.91}$ & $\mathrm{pH} 8.13$ & Water \\
\hline Fuji IX GP & $5.28(0.02)$ & $6.90(0.01)$ & $8.04(0.02)$ & $6.86(0.11)$ \\
Riva & $5.38(0.01)$ & $6.92(0.01)$ & $8.02(0.02)$ & $6.96(0.17)$ \\
Ketac Molar & $5.51(0.02)$ & $6.89(0.02)$ & $8.04(0.02$ & $7.10(0.32)$ \\
Chemfil Sup. & $5.62(0.05)$ & $6.97(0.02)$ & $8.03(0.04)$ & $7.16(0.12)$ \\
\hline
\end{tabular}

Table 4. Mass gain (\%) after 7 days in different storage media (standard deviations in parentheses).

\begin{tabular}{lccrr}
\hline Material & $\mathrm{pH} 5.42$ & $\mathrm{pH} 6.91$ & $\mathrm{pH} 8.13$ & Water \\
\hline Fuji IX GP & $0.65(0.11)$ & $-3.01(1.81)$ & $1.83(0.94)$ & $0.90(0.29)$ \\
Riva & $1.36(0.16)$ & $12.35(2.74)$ & $10.81(2.97)$ & $1.39(0.26)$ \\
Ketac Molar & $1.57(0.28)$ & $1.31(0.27)$ & $0.50(0.30)$ & $1.23(0.28)$ \\
Chemfil Sup. & $8.48(1.21)$ & $107.63(10.68)$ & $211.54(25.48)$ & $3.48(0.88)$ \\
\hline
\end{tabular}

Table 5. Compressive strength (MPa) after 7 days in different storage media (standard deviations in parentheses).

\begin{tabular}{lcccc}
\hline Material & $\mathrm{pH} 5.42$ & $\mathrm{pH} 6.91$ & $\mathrm{pH} 8.13$ & Water \\
\hline Fuji IX GP & $211.9(20.2)$ & $107.1(26.7$ & $125.4(8.6)$ & $216.2(31.2)$ \\
Riva & $213.7(48.7)$ & $112.1(8.5)$ & $44.8(19.4)$ & $223.3(10.6)$ \\
Ketac Molar & $210.7(11.2)$ & $196.9(15.3)$ & $197.0(15.3)$ & $190.6(24.8)$ \\
Chemfil Sup. & $139.5(19.1)$ & $47.7(23.6)$ & - & $173.5(9.0)$ \\
\hline
\end{tabular}


The reason for these differences is not clear. The alkaline buffer is presumably damaging because it is more strongly basic than the glass from which the cement was made, and so displaces the latter's products from the salt in the matrix. That being the case, the question arises why one material is completely resistant to attack. Even when the materials are affected, they are not all affected equally, as shown by the differences between the results for Fuji IX GP, Riva and Chemfil Superior. One additional feature of these results is the link between mass increase and weakening in the buffer at $\mathrm{pH} 8.31$. Ketac Molar had a net gain of $0.50 \%$ and a compressive strength close to $200 \mathrm{MPa}$; for the other cements, as mass gain was higher, so the weakening effect was greater. This connection shows that swelling and weakening are connected and the swelling shows that the storage medium damages the cement by some sort of chemical effect. However, exactly what this is and how the cement composition influences resistance to it is not clear.

For most materials, results in the buffer solution at pH 5.42 were similar to those in water in terms of both mass gain and compressive strength. The exception to this was Chemfil Superior, which was adversely affected by all three buffer solutions and performed well only when stored in distilled water.

Cements typically shifted the $\mathrm{pH}$ of the distilled water storage medium towards neutral. In doing so, they had modes gains in mass and good compressive strengths. Similar mass gains have been reported previously for glass-ionomer cements [19], and this water uptake seems to be characteristic of these materials. It is notable that Chemfil Superior took up significantly more water $(p<0.05)$ than the other three cements, though again the reason for this is unclear.

The buffer solution at $\mathrm{pH} 6.91$ proved to be surprisingly damaging to the cements Fuji IX GP, Riva and Chemfil Superior. In the latter case, the cement swelled substantially and was weakened considerably. Both Fuji IX GP and Riva were also weakened, though no as much as Chemfil Superior. The reason for these differences is not clear. The effect cannot be attributed to the $\mathrm{pH}$, as it is so close to neutral. Consequently there cannot have been any displacement reactions occurring within the cement to partly solubilise the components. Rather in some way the specific ions within the buffer solution must be responsible for weakening the cement matrix, though the mechanism for this is not known.

Previous studies have shown that a buffer solution of the appropriate $\mathrm{pH}$ can be highly aggressive towards glass-ionomer cements. Nomoto and McCabe demonstrated this with a lactate/lactic acid buffer at $\mathrm{pH} 2.74$, and found this medium to be very damaging to all the glass-ionomers in their study [23]. This was attributed to its low $\mathrm{pH}$, a suggestion with which we agree. However, our results have shown that $\mathrm{pH}$ values well away from neutral are not the only source of damage, as shown by the effects of the buffer solution at $\mathrm{pH}$ 6.91.
In the mouth, glass-ionomer cements are exposed to saliva, a natural buffer with a $\mathrm{pH}$ close to neutral. Values of salivary $\mathrm{pH}$ have been quoted as lying in the range 6-7 [24], but experimental studies suggest that the range may extend above 7, for example to 7.06 [25] or even as high as 7.89 [26]. There is evidence; too, that $\mathrm{pH}$ of saliva varies inter alia with the health of the patient [24-27], which suggests that glass-ionomers need to be capable of resisting attack by buffers across a range of $\mathrm{pH}$ values, possibly 5.5 to 8 .

Clinical results for glass-ionomers are generally good, and suggest that the saliva of real patients is not especially erosive [28]. Any erosion that does occur is generally attributed to acids in beverages, i.e. citric acid in lemon juice and orange juice, and malic acid in apple juice [29].

Overall, it is apparent that the interactions of glassionomer cements with buffer solutions are complicated, and not a simple function of $\mathrm{pH}$. One brand in our study was almost completely unaffected by the external medium, whereas another brand was substantially damaged by all three buffer solutions, including the one closest to neutral. Glass-ionomer cements themselves have the ability to alter the external $\mathrm{pH}$, an effect that has been called "buffering" $[20,30]$. In the present study, this effect was shown to be weak, at least compared with the buffering capacity of the storage solutions. Given that glass-ionomers meet saliva, a known biological buffer, in clinical use, further studies are needed to explore this topic further. In particular, identifying how glassionomers interact with external buffers is important in understanding how they perform in vitro.

\section{CONCLUSIONS}

Glass-ionomer cements vary in their response to exposure to buffer solutions and to distilled water, ranging from no measureable effect, to substantial swelling leading to considerable weakening. The features that cause this variation are not clear and need further investigation. Where cements are affected by buffer solutions, the solution with the $\mathrm{pH}$ closest to neutral causes the most damage. This shows that the effect of the buffer solution does not arise because of its acidity or basicity, but from some sort of unidentified interaction with the buffer solution.

\section{REFERENCES}

1. Sidhu S.K., Nicholson J.W. (2016): A review of glass-ionomer cements for clinical dentistry, Journal of Functional Biomaterials, 7, 16. doi: 10.3390/jfb7030016

2. Klos J., Czarnecka B., Nicholson J.W., Nowak, I., Wawrzyńczak, A. (2020): The effect of heat treatment of an ionomer glass on its surface characteristics and cement-forming properties, Ceramics-Silikaty, 64, 1-6. doi: 10.13168/cs. 2019.0042 
3. Khouw-Lui V.H.W., Anstice H.M., Pearson G.J. (1999): An in vitro investigation of a poly(vinyl phosphonic acid) based cement with four conventional glass-ionomer cements. Part 1: flexural strength and fluoride release, Journal of Dentistry, 27, 351-357. doi: 10.1016/s03005712(98)00061-x

4. Wilson A.D., Crisp S., Prosser H.J., Lewis B.G., Merson S.A. (1980): Aluminosilicate glasses for polyelectrolyte cements, Industrial and Engineering Chemistry Product Research and Development, 19, 263-270. doi: 10.1021/ i360074a027

5. Rafferty A., Hill R.G., Wood D.J. (2000): Amorphous phase separation of ionomer glasses, Journal of Materials Science, 35, 3863-3869. doi: 10.1023/A:1004885531712

6. Pedersen M.T., Tian K.V., Dobo-Nagy C, Chass G.A., Greaves G.N., Yue Y. (2015): Phase separation in an ionomer glass: Insight from calorimetry and phase transitions, Journal of Non-Crystalline Solids, 415, 24-29. doi: 10.1016/ j.jnoncrysol.2015.02.012

7. Crisp S., Pringeur M.A., Wardleworth D., Wilson A.D. (1974): Reactions in glass-ionomer cements. II. An infrared spectroscopic study, Journal of Dental Research, 53, 1414-1419. doi: 10.1177/00220345740530062001.

8. Nicholson J.W. (2018): Maturation in glass-ionomer dental cements, Acta Biomaterialia Odontologica Scandinavica 4, 63-71. doi: 10.1080/23337931.2018.1497492

9. Shahid S., Billington R.W., Pearson G.J. (2008): The role of the glass composition in the behaviour of glass acetic acid and glass lactic acid cements, Journal of Materials Science Materials in Medicine, 19, 541-545. doi: 10.1007/s10856007-0160-z

10. Atkins P., de Paula J.(2005). Elements of Physical Chemistry, $4^{\text {th }}$ ed., Oxford University Press.

11. Nicholson J.W., Amiri M.A. (1998): The interaction of dental cements with aqueous solutions of varying $\mathrm{pH}$, Journal of Materials Science Materials in Medicine, 9, 549-554,. doi: 10.1023/a:1008908523969

12. Nicholson J.W., Aggarwal A., Czarnecka B., LimanowskaShaw $\mathrm{H}$ (2000): The rate of change of $\mathrm{pH}$ of lactic acid exposed to glass-ionomer dental cements, Biomaterials, 21, 1989-1992. doi: 10.1016/s0142-9612(00)00085-5

13. De Maeyer E.A.P., Verbeeck R.M.H., Vercruysse C.W.J. (1999): Stoichiometry of the leaching process of fluoridecontaining aluminosilicate ionomer glasses, Journal of Dental Research, 78, 1312-1318. doi: 10.1177/00220345 990780070501

14. Lenander-Lumikari M., Loimaranta V. (2000): Saliva and dental caries, Advances in Dental Research, 14, 40-47. doi: 10.1177/08959374000140010601

15. Nicholson J.W., McKenzie M.A., Goodridge R, Wilson A.D. (2001): The effect of variations in the composition of storage media on the strength of dental cements, Journal of Materials Science Materials in Medicine, 12, 647-652. doi: 10.1023/a:1011202013025

16. Okada K., Tosaki S., Hirota K., Hume W.R. (2001): Surface hardness change of restorative filling materials stored in saliva, Dental Materials, 17, 34-39. doi: 10.1016/s01095641(00)00053-1
17. Petrovic B., Markovic D., Kojic S., Peric T., Dubourg G., Drljaca M., Stojanovic G. (2019): Characterization of glass-ionomer cements stored in various solutions, Materials \& Technology, 2, 285-293. doi: 10.17222/mit.2018.159

18. ISO 9917-1 (2003). Dental water based cements, International Organization for Standardization, Geneva, Switzerland.

19. Czarnecka B., Klos J., Nicholson J.W. (2015): The effect of ionic solutions on the uptake and water-binding behaviour of glass-ionomer dental cements, Ceramics-Silikaty,59, 292-297. doi: 10.1023/a:1008929923531

20. Czarnecka B., Limanowska-Shaw H, Nicholson J.W. (2002): Buffering and ion release by a glass-ionomer cement under near-neutral and acidic conditions, Biomaterials, 23, 2783-2788. doi: 10.1016/s0142-9612(02)00014-5.

21. Hasan AMHR, Sidhu SK, Nicholson J.W. (2019): The fluoride-release and uptake behaviour in enhanced bioactivity glass-ionomer cement ("glass carbomer ${ }^{\mathrm{TM}}$ ") compared with conventional and resin-modified glass-ionomer cements, Journal of Applied Oral Science., 27, e20180230. doi: 10.1590/1678-7757-2018-0230.

22. Forsten L. (1998): Fluoride release and uptake by glassionomers and related materials and its clinical effect, Biomaterials, 19, 503-508. doi: 10.1016/s0142-9612(97) 00130-0.

23. Nomoto R., McCabe J.F. (2001): A simple acid erosion test for dental water-based cements, Dental Materials, 17, 53-59. doi: 10.1016/s0109-5641(00)00058-0

24. Spielmann N., Wong D.T. (2011): Saliva: diagnostics and therapeutic perspectives, Oral Diseases, 17, 345-354. doi: 10.1111/j.1601-0825.2010.01773.x

25. Baliga S., Muglikar S, Kale R. (2013): Salivary pH: A diagnostic marker, Journal of the Indian Society of Periodontology, 12, 461-465. doi: 10.4103/0972-124X. 118317.

26. Seethalakshmi C., Redi R.C.J., Prabhu S. (2016): Correlation of salivary $\mathrm{pH}$, incidence of dental caries and periodontal status in diabetes mellitus patients: A aross-sectional study, Journal of Clinical and Diagnostic Research, 10, ZC12-ZC14. doi: 10.7860/JCDR/2016/16310.7351

27. Foglio-Bonda P.L., Brilli K., Pattarino F., Foglio-Bonda A. (2017): Salivary flow rate and $\mathrm{pH}$ in patients with oral pathologies, European Review of Medical and Pharmacological Science, 21, 369-374. PMID: 28165549

28. Gurgan S, Kutuk Z.B., Ergin E., Oztas S.S., Cakir F.Y. (2016): Clinical performance of a glass ionomer restorative system: a 6-year evaluation, Clinical Oral Investigations, 21, 2335-2343. doi: 10.1007/s00784-016-2028-4

29. Aliping-McKenzie M., Linden R.W.A., Nicholson J.W. (2003): The physical properties of conventional and resinmodified glass-ionomer dental cements stored in saliva, proprietary acidic beverages, saline and water, Biomaterials, 24, 4063-4069. doi: 10.1016/S0142-9612(03)00282-5

30. Nicholson J.W., Czarnecka B., Limanowska-Shaw H. (1999): A preliminary study of the effect of glass-ionomer and related dental cements on the $\mathrm{pH}$ of lactic acid storage solutions, Biomaterials, 20, 155-158. doi: 10.1016/s01429612(98)00153-7 